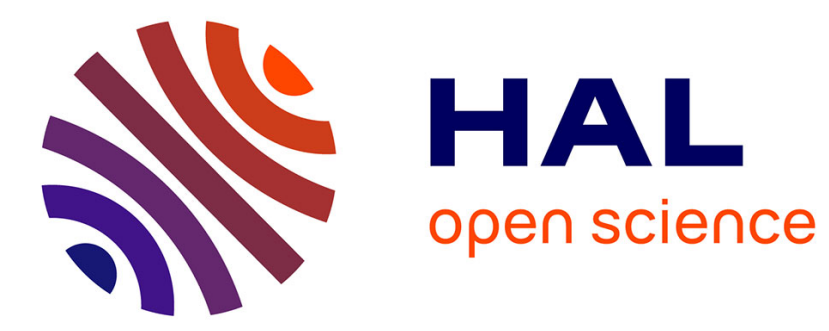

\title{
Developmental energetics of zebrafish, Danio rerio
}

Starrlight Augustine, Béatrice Gagnaire, Magali Floriani, Christelle

Adam-Guillermin, Sebastiaan A.L.M. Kooijman

\section{To cite this version:}

Starrlight Augustine, Béatrice Gagnaire, Magali Floriani, Christelle Adam-Guillermin, Sebastiaan A.L.M. Kooijman. Developmental energetics of zebrafish, Danio rerio. Comparative Biochemistry and Physiology - Part A: Molecular and Integrative Physiology, 2011, 159, pp.275 - 283. 10.1016/j.cbpa.2011.03.016 . hal-00759010

\section{HAL Id: hal-00759010 https://hal.science/hal-00759010}

Submitted on 30 Nov 2012

HAL is a multi-disciplinary open access archive for the deposit and dissemination of scientific research documents, whether they are published or not. The documents may come from teaching and research institutions in France or abroad, or from public or private research centers.
L'archive ouverte pluridisciplinaire HAL, est destinée au dépôt et à la diffusion de documents scientifiques de niveau recherche, publiés ou non, émanant des établissements d'enseignement et de recherche français ou étrangers, des laboratoires publics ou privés. 


\title{
Developmental Energetics of Zebrafish, Danio rerio
}

\author{
March 22, 2011
}

\author{
S. Augustine ${ }^{a 1}$, B. Gagnaire ${ }^{a}$, M. Floriani $^{a}$, C. Adam-Guillermin $^{a}$ and S.A.L.M. Kooijman ${ }^{b}$ \\ ${ }^{a}$ Laboratory of Radioecology and Ecotoxicology, DEI/SECRE/LRE, Institute of Radioprotection and Nu- \\ clear Safety (IRSN), Caradache, Building 186, BP3, 13115 St-Paul-lez-Durance Cedex, France \\ ${ }^{b}$ Department of Theoretical Biology, Vrije Universiteit, de Boelelaan 1087, 1081 HV Amsterdam, the \\ Netherlands
}

Starrlight AUGUSTINE e-mail: starr-light.augustine@irsn.fr, tel: 0033(0)442199413

Béatrice GAGNAIRE: beatrice.gagnaire@irsn.fr Magali FLORIANI: magali.floriani@irsn.fr

Christelle ADAM-GUILLERMIN: christelle.adam-guillermin@irsn.fr

Sebastiaan A. L. M. KOOIJMAN: bas@bio.vu.nl

Figures are designed to be reproduced in color on the web and in black-and-white in print.

\footnotetext{
${ }^{1}$ corresponding author
} 


\begin{abstract}
Using zebrafish (Danio rerio) as a case study, we show that the maturity concept of Dynamic Energy Budget (DEB) theory is a useful metric for developmental state. Maturity does not depend on food or temperature contrary to age and to some extent length. We compile the maturity levels for each developmental milestone recorded in staging atlases. The analysis of feeding, growth, reproduction and ageing patterns throughout the embryo, juvenile and adult life stages are well-captured by a simple extension of the standard DEB model and reveals that embryo development is slow relative to adults. A threefold acceleration of development occurs during the larval period. Moreover we demonstrate that growth and reproduction depend on food in predictable ways and their simultaneous observation is necessary to estimate parameters. We used data on diverse aspects of the energy budget simultaneously for parameter estimation using the covariation method. The lowest mean food intake level to initiate reproduction was found to be as high as 0.6 times the maximum level. The digestion efficiency for Tetramin ${ }^{\mathrm{Tm}}$ was around 0.5, growth efficiency was just 0.7 and the value for the allocation fraction to soma (0.44) was close to the one that maximizes ultimate reproduction.
\end{abstract}

Keywords: ageing, Danio rerio, development, Dynamic Energy Budget theory, feeding, growth, reproduction 


\section{Introduction}

Experimental evidence points to developmental processes being heterochronic and they play an important role in evolutionary theory (McKinney and McNamara, 1991). Spicer and Burggren (2003) propose the concept of heterokairy to study how changes in the sequence of developmental events relate to changes in the timing of physiological regulatory systems and/or its components. Theoretical progress in the analysis of these processes lags behind experimental work for lack of a quantifier for internal time which does not necessarily correlate with morphological (e.g. length) or chronological (e.g. age) criteria (Reiss, 1989). The objective of the present study is to provide a such a quantifier for the rate of development of the individual. We focus on zebrafish Danio rerio since it is widely used to study development (Kimmel et al., 1995; Parichy et al., 2009). A growing number of disciplines use zebrafish as a model with the consequence that numerous observations on life history traits, under laboratory controlled conditions, are available (Laale, 1977; Gerhard and Cheng, 2002; Lawrence, 2007; Spence et al., 2008).

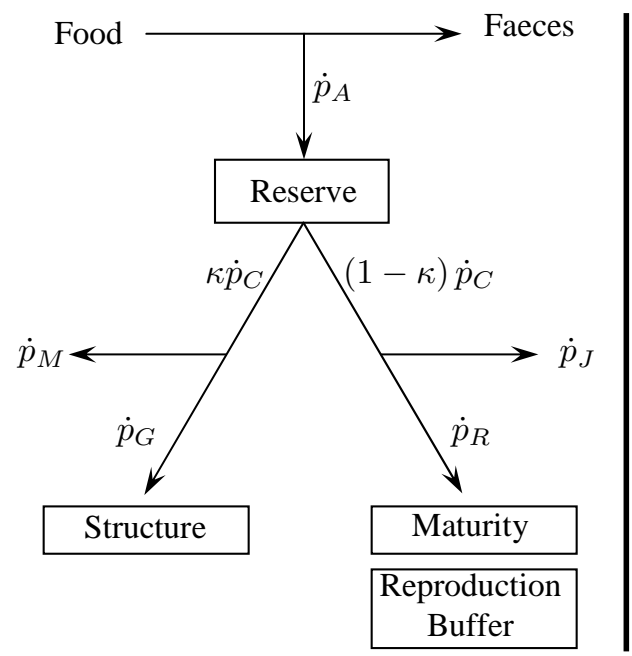

$\dot{p}_{A}$ : Assimilation

$\dot{p}_{C}$ : Mobilization

$\kappa$ : Fraction of $\dot{p}_{C}$ mobilized

towards growth and

somatic maintenance

$\dot{p}_{M}$ : Somatic maintenance

$\dot{p}_{J}:$ Maturity maintenance

$\dot{p}_{G}:$ Growth

$\dot{p}_{R}$ : Maturity then Reproduction

Figure 1: Conceptual organisation of animal metabolism as defined by DEB theory (Kooijman, 2010). Arrows: energy fluxes $\left(\mathrm{J} \mathrm{d}^{-1}\right)$; boxes: state variables of the system. Embryo: $\dot{p}_{A}=0$; birth: assimilation is switched on; puberty: allocation to maturity $E_{H}$ stops and allocation to reproduction $E_{R}$ starts. Energy allocated to reproduction accumulates in the reproduction buffer and is emptied at spawning.

We undertake a theoretical analysis of zebrafish development over its entire life cycle using Dynamic Energy Budget (DEB) theory (Kooijman, 2001, 2010), see Sousa et al. (2010) an introduction to the theory. The theory quantifies the uptake and use of substrates (food) by organisms, see figure 1. Stage transitions, such as from embryo to juvenile (defined as the initiation of feeding) and from juvenile to adult (defined as the ceasing of further maturation and the initiation of allocation to reproduction) are linked to the 
level of maturity. Maturity is quantified as the cumulated energy invested in development. Although the standard DEB model has been applied to a wide variety of animals (Zonneveld and Kooijman, 1993; van der Veer et al., 2010; Bodiguel et al., 2009; Flye-Sainte-Marie et al., 2009; Pecquerie et al., 2009; Rico-Villa et al., 2010), tests that the parameters for the embryo, juvenile and adult are all the same are relatively rare (Kooijman et al., 2011; Lika et al., 2011). We collected a number of detailed studies on the growth, reproduction and ageing of zebrafish, and we also did a growth-and-reproduction experiment at three feeding levels, to estimate the parameters of the standard DEB model and judge if the full life cycle could be captured with a single set of parameter values. We discuss the coupling of developmental milestone to age and size at stage transitions (e.g. birth and puberty) and give a mechanistic underpinning of effects of food and temperature.

\section{$2 \quad$ DEB model}

The conceptual organisation of metabolism, described in the DEB model, is presented in figure 1. The mobilisation of reserve $\dot{p}_{C}$ is such that weak homeostasis is respected, i.e. the ratio of the amounts of reserve $E(\mathrm{~J})$ and structure $V\left(\mathrm{~cm}^{-3}\right)$, called the reserve density $[E]$, is constant at constant food densities in juveniles and adults. The increase in the maturity level $E_{H}(\mathrm{~J})$, called maturation, is by allocating a fixed fraction of mobilised reserve $(1-\kappa) \dot{p}_{C}$ after subtraction of maturity maintenance costs $\dot{p}_{J}$ (e.g. immune system, hormonal regulation, anti-oxidative stress system). $\dot{p}_{J}=\dot{k}_{J} E_{H}$, with $\dot{k}_{J}\left(\mathrm{~d}^{-1}\right)$ the maturity maintenance rate coefficient. Positive maturity maintenance implies that reproduction is absent at low food levels. There is no assimilation during the embryonic period, i.e. when $E_{H}<E_{H}^{b}$, with $E_{H}^{b}$ the cumulated amount of energy invested in maturity at birth.

From birth onwards reserve is replenished by assimilation, $\dot{p}_{A}\left(\mathrm{~J} \mathrm{~d}^{-1}\right)$. We now explain how assimilation is linked to actual ingestion. Ingestion rate, $\dot{p}_{X}\left(\mathrm{~J} \mathrm{~d}^{-1}\right)$, is a function of food density and is taken proportional to surface area $L^{2}$, with $L=V^{1 / 3}$ the (volumetric) structural length of an organism. $\dot{p}_{X}$ is quantified by the scaled functional response (ingestion level) $f$, defined as the ratio of actual ingestion rate and the maximum possible one for an individual of that size. This makes $\dot{p}_{X}=f\left\{\dot{p}_{X m}\right\} L^{2}$, where $\left\{\dot{p}_{X m}\right\}\left(\mathrm{J} \mathrm{d}^{-1} \mathrm{~cm}^{-2}\right)$ is the maximum surface area specific ingestion rate. The conversion efficiency of food to reserve (digestion efficiency), $\kappa_{X}$, is specific to each type of food. Finally, $\dot{p}_{A}=\kappa_{X} \dot{p}_{X}$. Digestion efficiency is calculated using the following relationship:

$$
\kappa_{X}=\left\{\dot{p}_{A m}\right\} /\left\{\dot{p}_{X m}\right\}
$$

where $\left\{\dot{p}_{A m}\right\}\left(\mathrm{J} \mathrm{d}^{-1} \mathrm{~cm}^{-2}\right)$ is the maximum surface-area specific assimilation rate and a model parameter (see table 1 ).

Growth is defined as the increase of structure. Energy allocated to growth $\dot{p}_{G}$ is a fixed fraction of mobilised reserve $\kappa \dot{p}_{C}$ after subtraction of somatic maintenance costs $\dot{p}_{M}=\left[\dot{p}_{M}\right] V$ (e.g maintaining intra-cellular concentration, protein turnover, movement), with $\left[\dot{p}_{M}\right]\left(\mathrm{J} \mathrm{d}^{-1} \mathrm{~cm}^{-3}\right)$ the volume-specific maintenance costs. The cost of the synthesis of a unit of structure is called $\left[E_{G}\right]\left(\mathrm{J} \mathrm{cm}^{-3}\right)$ which indirectly defines growth efficiency 
$\kappa_{G}$ being the ratio of energy fixed and invested in new structure (see table A.3, online appendix A).

Allocation to maturation in juveniles is redirected to reproduction in adults $\left(\dot{p}_{R}\right)$ at puberty which occurs at $E_{H}=E_{H}^{p}$. Reserve allocated to reproduction is first accumulated in a buffer which is emptied at spawning. The conversion of reserve to egg (embryo reserve) occurs with efficiency $\kappa_{R}$. The value of 0.95 in table 1 has been chosen in view of the absence of substantial chemical work. Allocation to growth and somatic maintenance occurs in parallel to allocation to maturation and reproduction (see figure 1). The embryo starts its development with zero structure and maturity, and an amount of reserve such that the reserve density at birth equals that of the mother at egg formation. The latter condition is a maternal effect Kooijman (2009).

Table 1: State variables and primary parameters (affecting changes of state variables at $20^{\circ} \mathrm{C}$ ) of the zebrafish DEB model, and other parameters (see text).

\begin{tabular}{|c|c|c|c|}
\hline Symbol & Value & Unit & Name \\
\hline \multicolumn{4}{|c|}{ State Variables } \\
\hline$E$ & - & $J$ & Reserve \\
\hline$V$ & - & $\mathrm{cm}^{3}$ & Structure \\
\hline$L$ & - & $\mathrm{cm}$ & Structural length $V^{1 / 3}$ \\
\hline$E_{H}$ & - & $\mathrm{J}$ & $\begin{array}{l}\text { Cumulated energy invested in maturity uptill } \\
\text { puberty and reproduction after puberty }\end{array}$ \\
\hline \multicolumn{4}{|c|}{ Primary Energy Parameters } \\
\hline$\left\{\dot{p}_{A m}\right\}$ & 246.3 & $\mathrm{~J} \mathrm{~d}^{-1} \mathrm{~cm}^{-2}$ & $\begin{array}{l}\text { Embryo Maximum surface area specific assimilation } \\
\text { rate }\end{array}$ \\
\hline$\dot{v}$ & 0.0278 & $\mathrm{~cm} \mathrm{~d}^{-1}$ & Embryo Energy conductance \\
\hline$\kappa$ & 0.437 & - & $\begin{array}{l}\text { A specific fraction of energy mobilized from reserve } \\
\text { allocated to growth and somatic maintenance }\end{array}$ \\
\hline$\kappa_{X}$ & 0.5 & - & Digestion efficiency for Tetramin ${ }^{\mathrm{TM}}$ \\
\hline$\kappa_{R}$ & 0.95 & - & Reproduction efficiency \\
\hline$\left[\dot{p}_{M}\right]$ & 500.9 & $\mathrm{~J} \mathrm{~d}^{-1} \mathrm{~cm}^{-3}$ & Volume specific somatic maintenance costs \\
\hline$\dot{k}_{J}$ & 0.0166 & $\mathrm{~d}^{-1}$ & Maturity maintenance rate \\
\hline$\left[E_{G}\right]$ & 4652 & $\mathrm{~J} \mathrm{~cm}^{-3}$ & Cost of synthesis of a unit of structure \\
\hline$E_{H}^{b}$ & 0.54 & $\mathrm{~J}$ & Cumulated energy invested in maturity at birth \\
\hline$E_{H}^{j}$ & 19.66 & $\mathrm{~J}$ & $\begin{array}{l}\text { Cumulated energy invested in maturity at } \\
\text { metamorphosis }\end{array}$ \\
\hline$E_{H}^{p}$ & 2062 & $\mathrm{~J}$ & Cumulated energy invested in maturity at puberty \\
\hline \multicolumn{4}{|c|}{ Other parameters } \\
\hline$T_{A}$ & 3000 & $\mathrm{~K}$ & Arrhenius Temperature \\
\hline$\ddot{h}_{a}$ & $1.9610^{-9}$ & $d^{-2}$ & Weibull aging acceleration \\
\hline$s_{G}$ & 0.0405 & - & Gombertz stress coefficient \\
\hline$\delta_{\mathcal{Y}}$ & 0.1325 & - & Shape coefficient for embryos \\
\hline$\delta_{\mathcal{M}}$ & 0.1054 & - & Shape coefficient juveniles and adults for total length \\
\hline
\end{tabular}

The standard DEB model assumes that the individual is isomorphic, i.e. it does not change in shape during growth, which makes that surface area is proportional to volume to the power 2/3. Motivated by studies on Anchovy, Engraulis encrasicolus, and Bluefin 
Tuna, Thunnus orientalis, (Pecquerie, 2007; Jusup et al., 2010), we implemented the possibility that development accelerates after birth $\left(E_{H}=E_{H}^{b}\right)$ by including a V1-morphic stage (surface area grows proportional to volume) for the larva (early juvenile) till maturity reaches a threshold level for metamorphosis $\left(E_{H}=E_{H}^{j}\right)$, after which growth resumes in an isomorphic fashion (Kooijman et al., 2011). If $E_{H}^{j}=E_{H}^{b}$ there is no acceleration, but if $E_{H}^{j}>E_{H}^{b}$ both $\left\{\dot{p}_{A m}\right\}$ and energy conductance $\dot{v}\left(\mathrm{~cm} \mathrm{~d}^{-1}\right)$ increase with length. $\dot{v}$ controls reserve mobilization.

Auxiliairy theory assumes that the shape coefficient $\delta$, i.e. the ratio of structural length $(L)$ and physical observed length $L_{\text {obs }}$, is constant for isomorphs. Shape changes during the early juvenile (V1-morphic) period are described by the empirical function $\delta(L)=\delta_{\mathcal{M}}+\left(\delta_{\mathcal{Y}}-\delta_{\mathcal{M}}\right) \frac{L_{j}-L}{L_{j}-L_{b}} \quad$ for $\quad L \in\left[L_{b}, L_{j}\right]$ with $\delta_{\mathcal{Y}}$ and $\delta_{\mathcal{M}}$ shape coefficients for embryos and adults respectively, $L_{b}$ structural length at birth and $L_{j}$ structural length at metamorphosis.

The effect of temperature on all biological rates is well captured by the Arrhenius relationship (Kooijman, 2010), quantified by the Arrhenius temperature $T_{A}$. This relationship only holds within a particular temperature tolerance range.

DEB theory considers development and senescence to be parallel processes. The ageing module of DEB theory (Kooijman, 2010; van Leeuwen et al., 2010) specifies that the induction of damage inducing compounds (e.g. modified mitochondrial DNA) is proportional to the mobilisation rate of reserve, which is (about) proportional to the use of dioxygen (linking to free radicals) that is not associated with assimilation. Damage inducing compounds can also induce themselves at a rate that is proportional to their concentration and, again, to the mobilisation rate of reserve as quantifier for metabolic activity. Damage inducing compounds induce damage compounds (e.g. modified proteins) which accumulate in the body. The hazard rate due to ageing is taken proportional to the density of damage compounds. This specifies the ageing module, and how ageing depends on energetics, and so on the nutritional status of the organism.

\section{Materials and methods}

\subsection{Caloric restriction experiment}

We designed a caloric restriction experiment to obtain quantitative data on growth in combination with reproduction at 3 ingestion levels for individual fish.

$2 \mathrm{~cm}$ (SL) fish were acquired from a commercial fish breeder (Elevage de la grande rivière, Lyon, France) and were 116 days post-fertilization (dpf) upon arrival. Based on this size and age we estimated the mean intake level $f_{\text {cult }}$. Animals were kept in soft water: $\mathrm{T}=26 \pm 0.6^{\circ} \mathrm{C}, \mathrm{pH}=6.5 \pm 0.4$, electrical conductivity $200 \mu \mathrm{S} \mathrm{cm}^{-1}$. Food given was Tetramin $^{\text {тм }}$ (proteins, $46 \%$, lipids $7.0 \%$, ash $10.0 \%$ cellulose $2.0 \%$ and moisture $8.0 \%$ ). We calculated the energetic content of Tetramin as $19.1 \mathrm{~kJ} \mathrm{~g}^{-1}$ with 17.2 and $38.9 \mathrm{~kJ} \mathrm{~g}^{-1}$ for lipids and proteins respectively (Kooijman, 2010, table 4.2). This result is used to obtain $\kappa_{X}$ (see equation 1) for individuals during acclimatization (116 and $132 \mathrm{dpf}$ ), where

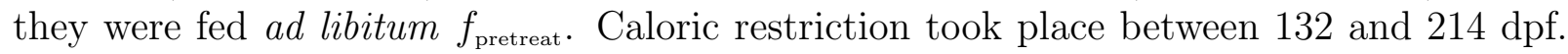


We started with 6, 4.5 and $3 \mathrm{mg}$ Tetramin per day per individual fish for the first $\left(f_{1}\right)$, second $\left(f_{2}\right)$ and third $\left(f_{3}\right)$ ingestion level respectively. $f_{1}$ and $f_{2}$ were gradually raised to $10 \mathrm{mg}$ tetramin $\mathrm{d}^{-1}$ while $f_{3}$ remained constant during the caloric restriction phase, in accordance with the expectation that feeding rate is proportional to squared length. The daily ration was hand weighed in aluminium micro weighing dishes (VWR) with an SE2 ultra-microbalance (Sartorius AG, Göttingen, Germany) and dispensed 2 to 3 times throughout the day. Individuals fasted one day per week. The experimental system is fully characterized in the online appendix D. We kept 20 individuals per condition. Reproduction was assessed by forming couples (1:1 male to female ratio) in the evening and counting the number of eggs spawned the following morning. We followed the daily egg output of individual females over two successive breeding trials which lasted 22 and 15 days respectively.

To check the condition of the gonads three males and three females in each condition were sacrificed at the end of the experiment. Gonads were removed and immersed in $2.5 \%$ glutaraldehyde sodium cacodylate buffer $(0.1 \mathrm{M}, \mathrm{pH} 7.4)$ for $24 \mathrm{~h}$ at $4^{\circ} \mathrm{C}$ then post fixed with $1 \%$ osmium tetroxyde for $1 \mathrm{~h}$. The samples were dehydrated through a graded ethanol series and finally embedded in monomeric resin Epon 812. Semi-thin sections for light microscopy analysis $(500 \mathrm{~nm})$ were obtained with an ultramicrotome UCT (Leica Microsystems GmbH, Wetzlar, Germany). Plastic sections were stained with aqueous blue toluidine and gonad structure was examined under a light microscope (Leica, DM750) equipped with a Leica camera ICC50 and LAS EZ Software. For each replicate, at least 20 micrographs of local detailed structures were taken, analysed and compared.

\subsection{Data and parameter estimation}

We incorporated real and pseudo data into the parameter estimation routine. Real data, compiled from the literature and the caloric restriction experiment, include observed lengths, weights, reproduction, and survival at single (0-variate) or multiple (1-variate) time and/or temperatures points. Pseudo data represent the more conserved aspects of animal metabolism; large deviations from these data are considered to be less likely. The pseudo data concern: $\dot{v}=0.02 \mathrm{~cm} \mathrm{~d}-1,\left[\dot{p}_{M}\right]=18 \mathrm{~J} \mathrm{~d}^{-1} \mathrm{~cm}^{-3}, \kappa=0.8, \kappa_{G}=0.8$ and $\dot{k}_{J}=0.002 \mathrm{~d}^{-1}$ (see Kooijman, 2010, pp.300). The chemical indices (c-mol per c-mol), molar weights ( $\mathrm{g} \mathrm{mol}^{-1}$ ), and chemical potentials $\left(\mathrm{J} \mathrm{mol}^{-1}\right)$ and are as given in Lika et al. (2011) (table A.1, online appendix A). The densities $d_{V d}$ and $d_{E d}\left(\mathrm{~g} \mathrm{~cm}^{-3}\right)$ for structure and reserve were derived from Craig and Fletcher (1984) (table A.1, online appendix A).

We allowed expectations to deviate from these values by giving them less weight relative to real data. We converted all rates and ages to a reference temperature of $20^{\circ} \mathrm{C}$. We measured the ratio of standard length SL (tip of snout till base of caudal fin) and total length TL (tip of snout to end of caudal fin) of 70 adult zebrafish (Adam-Guillermin unpublished 2009) and found an average ratio of 0.8. DEB model predictions are given in TL so when necessary the predictions are corrected to standard length SL. We treated forked length FL (tip of snout till fork in the caudal fin) equal to TL.

We applied the method of covariation for parameter estimation (Lika et al., 2011) using the freely downloadable software DEBtool (Kooijman et al., 2008). This software uses the 
Table 2: Model predictions for 0-variate data are compared with observations.

\begin{tabular}{lllll}
\hline Data & $\begin{array}{l}\text { Observa- } \\
\text { tions }\end{array}$ & $\begin{array}{l}\text { Predic- } \\
\text { tions }\end{array}$ & Unit & Reference \\
\hline $\begin{array}{l}\text { size at birth } \\
\text { maximum length (TL) }\end{array}$ & 0.39 & 0.40 & $\mathrm{~cm}$ & $\begin{array}{l}\text { Schilling (2002) } \\
\text { Spence et al. (2008); Schilling } \\
\text { (2002) }\end{array}$ \\
$\begin{array}{l}\text { maximum } \\
\text { reproduction rate }\end{array}$ & $5.00-240$ & 113.6 & $\#$ eggs d $^{-1}$ & $\begin{array}{l}\text { Eaton and Farley (1974a) and } \\
\text { Geffroy (Unpublished 2009) }\end{array}$ \\
$\begin{array}{l}\text { egg dry mass } \\
\text { geg diameter }\end{array}$ & $30-106$ & 73 & $\mu \mathrm{c}$ & $\begin{array}{l}\text { Augustine (Unpublished 2010) } \\
\text { maximum wet weight }\end{array}$ \\
\hline & $0.08-0.09$ & 0.10 & $\mathrm{~cm}$ & Uusi-Heikkila et al. (2010) \\
& & 0.99 & $\mathrm{~g}$ & Pers. Obs \\
\hline
\end{tabular}

simplex (Nelder-Mead) method to simultaneously minimise the weighted sum of squared deviations between model predictions and observations for a considerable number of data sets. Computations were performed with Matlab ${ }^{\odot}$ (version 7.9.0.529). DEBtool routines and formula for calculating predictions for data in table 2 be found in table A.3 (online appendix A). Without information on mass and caloric content of food ingested per day we could not calculate the digestion efficiency each food type described in the data from the literature. We make the assumption that while diets differ between experiments they are similar enough for us to apply a scaled functional response $0 \leq f \leq 1$ for all data. $f$ is a free parameter and is estimated for each data set. Although we could suppose constant food density and temperature for most data (section A.1, online appendix A), a dynamic formulation of the model was needed to predict growth and reproduction in the caloric restriction experiment (section A.2, online appendix A).

\section{Results}

The conversion efficiency of Tetramin ${ }^{\text {тм }}$ to reserve was found to be $\kappa_{X}=0.5$. Parameter estimates (table 1) show a factor 40 difference between maturity level at metamorphosis and at birth $\left(E_{H}^{j}\right.$ and $\left.E_{H}^{b}\right)$ which translates into a factor 3 difference in structural lengths $\left(L_{j}\right.$ and $\left.L_{b}\right)$ at abundant food. So specific assimilation and energy conductance also increase by a factor 3 during the early juvenile period. Drain to maturity maintenance amounts to $34.27 \mathrm{~J} \mathrm{~d}^{-1}$ in adults and only a fraction $1-\kappa=0.56$ of mobilized reserve is allocated to maturity maintenance plus reproduction. This implies that puberty is not reached for ingestion levels lower than $f=0.6$. We were surprised that the lowest intake level for reproduction is that high. The value for $\kappa$ is very close to the one which maximizes the ultimate reproduction rate (0.48) given the values of the other parameters. The Add_My_Pet collection typically shows values around 0.8 for which reproduction is far below the maximum possible one (Lika et al., 2011). Some $44 \%$ of the initial energy in an egg is lost by the end of the embryonic period (birth), see figure 3, by mineralization of reserve. Although maintenance is relatively high (see the Add_My_Pet collection) the cumulative amount spent at birth is small due to high costs for growth and maturation. Energy conductance is typical for embryos and relatively high for adults due to the acceleration during the early 


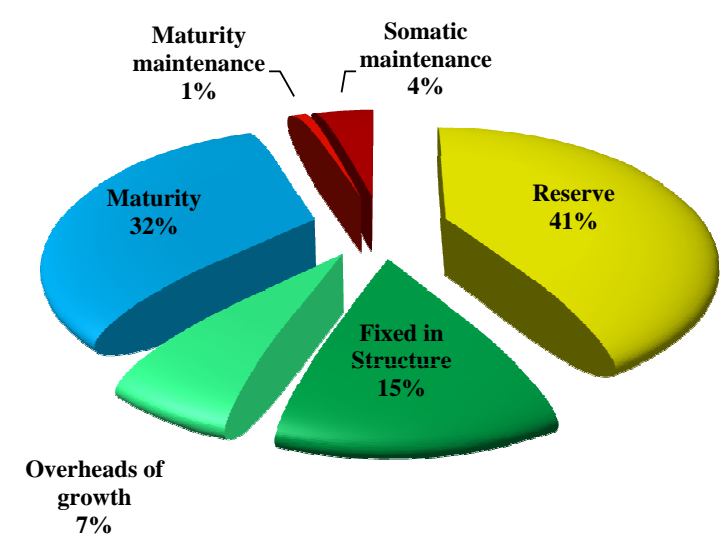

Figure 2: Energy budget at birth when the mother was at abundant food. Initial reserve in an egg $\left(E_{0}\right)$ is $1.670 \mathrm{~J}$ while structure and maturity are zero. Slices represent the cumulated energy investments at birth relative to $E_{0}$. Maturity (cumulated energy invested in maturity) as well as maturity and somatic maintenance are dissipated in the environment as minerals (e.g. $\left.\mathrm{CO}_{2}\right)$. A fraction $1-\kappa_{G}$ of energy invested in structure is lost as overheads of growth. The reserve and structure contribute to the actual mass of the organism at birth.

juvenile period.

Compiled growth curves (figure 3) are confronted with DEB predictions and we conclude that general growth patterns are accurately predicted by DEB theory for ingestion levels ranging from 0.4 in Bagatto et al. (2001) to 0.88 in Gómez-Requeni et al. (2010). Predicted egg dry mass ranges from 58 to $73 \mu \mathrm{g}(f=0.5$ to $f=1)$. Maximum predicted wet weight for a fish is $0.99 \mathrm{~g}$.

Age dependent survival was correctly predicted (see figure 4 and section A.3, online appendix A for equations). Lifespan is expected to decrease for increasing food. The ultimate size of the fish of around $3.5 \mathrm{~cm}$ SL (Gerhard et al., 2002, pers. comm.) suggests that $f \approx 0.8$. figure 4 also presents model predictions for abundant food.

Predicted length at birth (4 $\mathrm{mm}$ at abundant food table 2$)$ is not very sensitive to the nutritional status of the mother which is in line with both Parichy et al. (2009) (developmental milestone pSB+: inflation of posterior swim bladder, head showing anterior mouth position) and Schilling (2002)(length at first feeding). DEB theory predicts that age at birth also depends on ingestion level of the mother (maternal effect). However the effect is minimal. According to Kimmel et al. (1995) 'birth' (active feeding behaviour) is around 5 dpf at $28.5^{\circ} \mathrm{C}$. DEB theory predicts birth in the range of 4.3 to $4.7 \mathrm{dpf}(f=1$ to $f=0.5)$ at $28.5^{\circ} \mathrm{C}$ and in the range of 4.8 to $5.3 \mathrm{dpf}(f=1$ to $f=0.5)$ at $25^{\circ} \mathrm{C}$.

The Arrhenius relationship for the log of developmental age against inverse temperature should be linear. Figure 5 confirms this for different developmental milestones and also presents model predictions for age at birth. We see (a) that the estimated Arrhenius temperature of $3000 \mathrm{~K}$ (which corresponds graphically to the regression slope) is coherent with observations and (b) that birth occurs just after the protruding mouth stage described by Kimmel et al. (1995). Typical Arrhenius temperatures revolve around $8000 \mathrm{~K}$ 

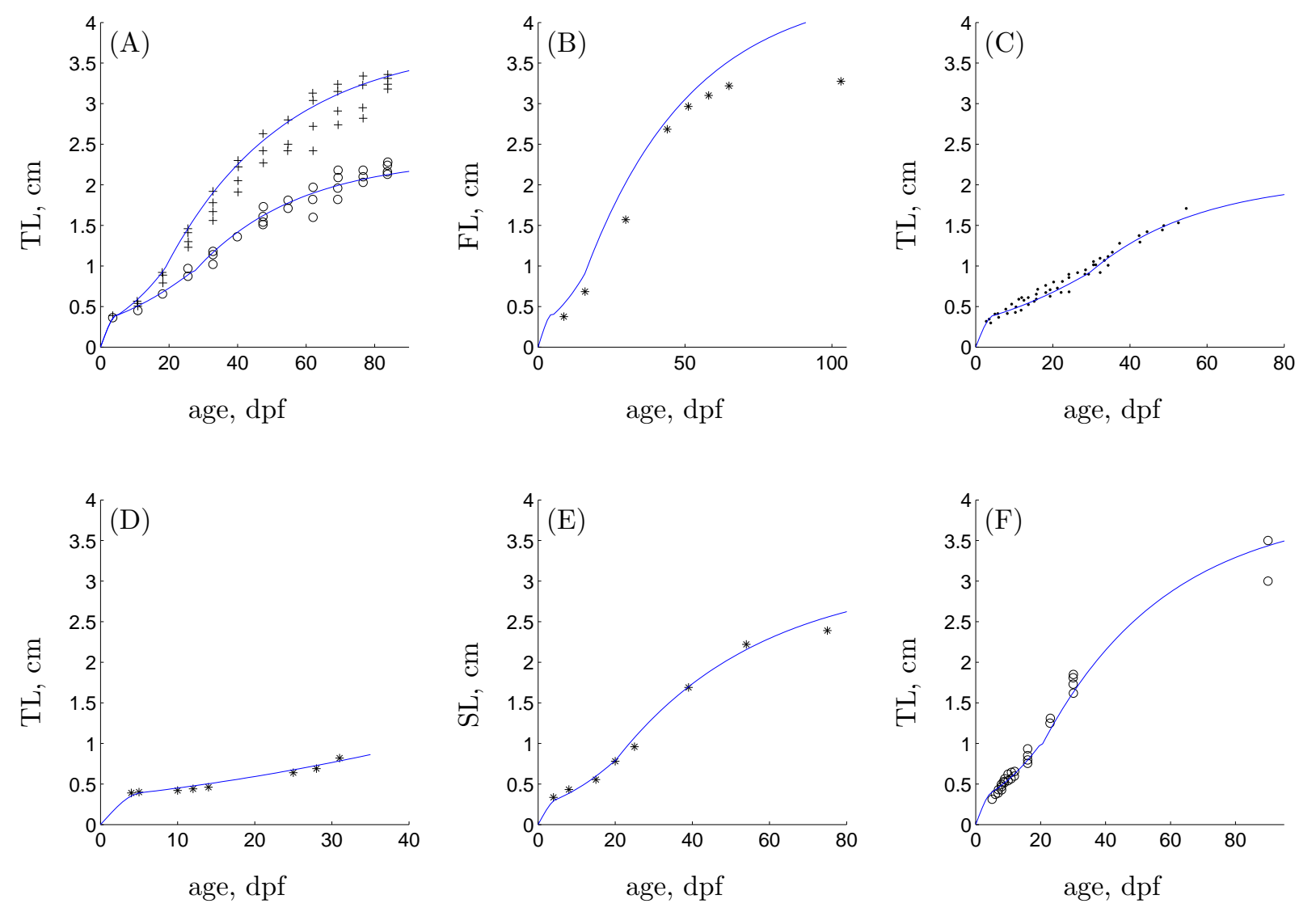

Figure 3: Synthesis of model predictions against observed lengths of fish from different published studies. Crosses or circles: observations; full lines: model predictions; TL: Total Length (snout till end of caudal fin); FL: Forked Length (snout till fork in caudal fin); SL: Standard Length (snout till base of caudal fin). For each data set we specify temperature and estimated ingestion level $f$ $(0 \leq f \leq 1)$. (A) Data from Lawrence et al. (2008) and pers. comm.. $T=28.5^{\circ} \mathrm{C} ;(+)$ individuals fed approximately twice as much as (o). $f_{1}=0.75$ for high ingestion level and $f_{2}=0.65 f_{1}$ for the lower ingestion level. (B) Data from Gómez-Requeni et al. (2010). $T=28^{\circ} \mathrm{C} ; f=0.88$. (C) Data from Schilling (2002); $T=28.5^{\circ} \mathrm{C} ; f=0.44$. (D) Data from Bagatto et al. (2001). $T=25^{\circ} \mathrm{C}$; $f=0.4$. The type of length measurement is unknown but model predictions are in TL. (E) Data from (Eaton and Farley, 1974a). $T=25.5^{\circ} \mathrm{C} ; f=0.77$. (F) Data from Best et al. (2010) but we present the full growth curve provided through pers. comm. with C. Lawrence. $T=25^{\circ} \mathrm{C}$; $f=0.78$. 


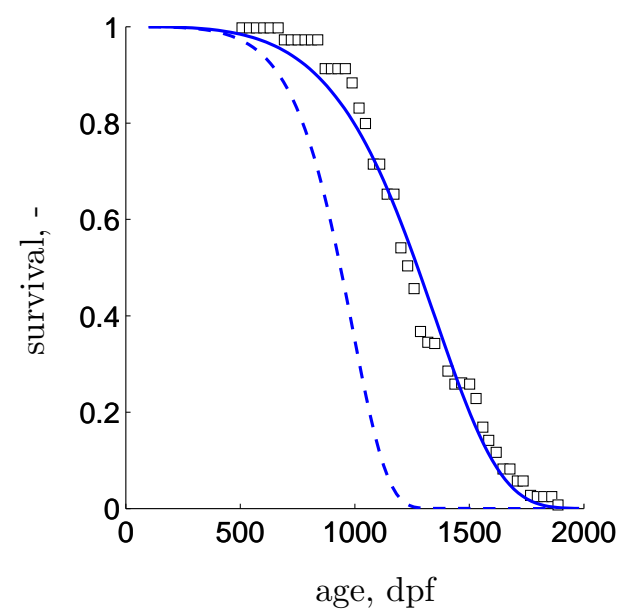

Figure 4: Survival probability in relation to nutritional status as predicted by the DEB ageing module. ( $\square$ ) data from Gerhard et al. (2002) outbred tank 2; solid line: model prediction for $f=0.8$. Dashed line: predicted survival for $f=1$. $\mathrm{T}=26^{\circ} \mathrm{C}$.

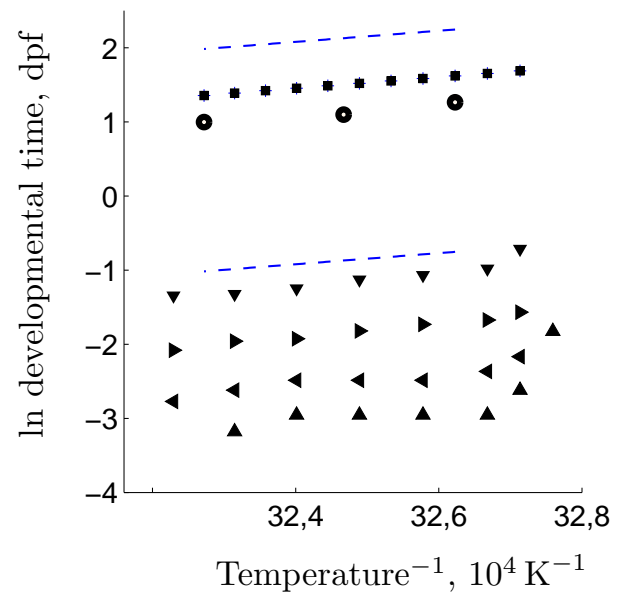

Figure 5: Ln developmental age as a function of inverse temperature. Model predictions for

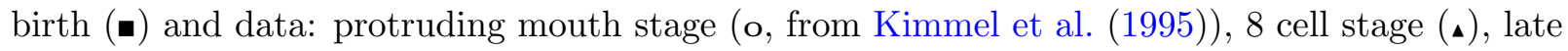
cleavage (४), very late blastula $(\bullet)$, and blastoderme $3 / 4$ yolk sphere $(\mathbf{v})$, all from Shirone and Gross (1968). The slope of the dashed lines gives an Arrhenius temperature of $3000 \mathrm{~K}$. 
(Add_My_Pet) making zebrafish less sensitive to temperature variations.
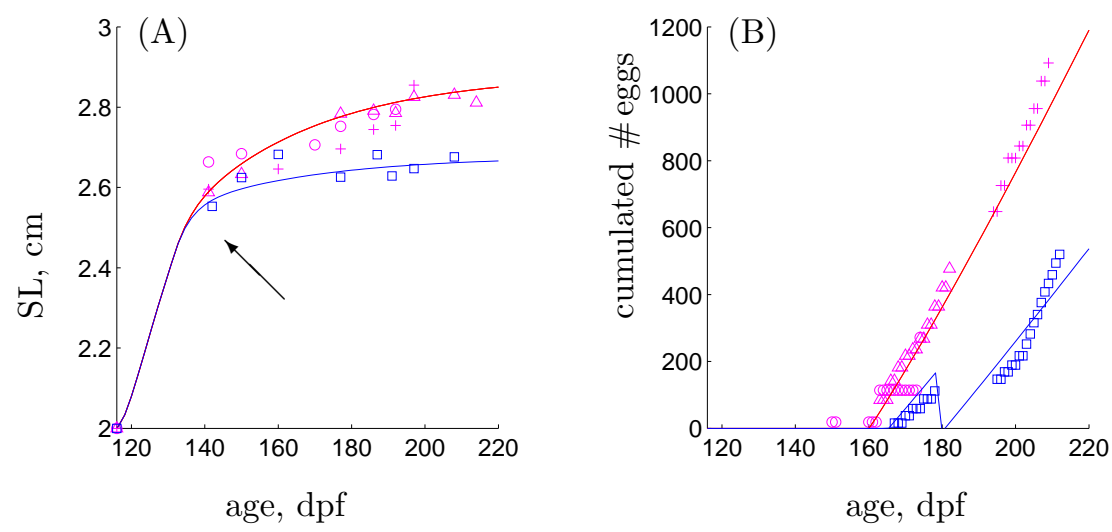

Figure 6: Observations, the symbols refer to the different individuals, and model predictions, solid lines, for growth (A) and reproduction (B) during 82 days of caloric restriction at two feeding levels which are estimated at $f_{1}=0.74$ and $f_{2}=0.69$. Animals are 116 days post-fertilization (dpf) and $2 \mathrm{~cm}$ standard length SL (tip of snout till base of caudal fin) at arrival. They are acclimated to laboratory conditions for two weeks. Caloric restriction is initiated at $132 \mathrm{dpf}$ (arrow).

For $f=0.77$ (figure 3, E) first spawns occurred at 71-75 dpf for females between 2.4 and $2.6 \mathrm{~cm} \mathrm{SL}$ at $25.5^{\circ} \mathrm{C}$ (Eaton and Farley, 1974b). Predicted age and length at puberty for this data set is $88 \mathrm{dpf}$ and $2.7 \mathrm{~cm}$ SL. Not only these data but also the complete growth curve is in remarkable agreement.

This agreement also applies to the growth and reproduction in our caloric restriction experiment (figure 6) $\left(f_{\text {cult }}=0.55, f_{\text {pretreat }}=0.9, f_{1}=0.74\right.$ and $\left.f_{2}=0.69\right)$. Predicted ages at puberty are $160 \mathrm{dpf}$ and $165.5 \mathrm{dpf}$ and predicted reproduction rates are 19.84 and 13.01 eggs per day for $f_{1}$ and $f_{2}$ respectively at $26^{\circ} \mathrm{C}$. Maximum predicted reproduction rate (table 2) at $26^{\circ} \mathrm{C}$ at abundant food is 113.6 eggs per day. This value represents the maximum daily energy invested in reproduction by the largest possible individual $\left(L=L_{m}\right)$ at highest ingestion level $(f=1)$.

Length at puberty ranges from $2.9(f=0.6)$ to $3.8(f=1) \mathrm{cm}$ TL $(2.3-3 \mathrm{~cm} \mathrm{SL})$ and age at puberty ranges from $178.8-59.18 \mathrm{dpf}$ at $28^{\circ} \mathrm{C}$. Contrary to age and length maturity levels at various developmental milestones are independent of temperature and nutritional status, see tables 3 and 4. Maturity levels are computed using parameters values in table 1. Standardized Standard Lengths (SSL) as given by Parichy et al. (2009) are converted to total lengths using their photographs for each milestone. The contribution of the caudal fin changes during development from 0.06 at birth to 0.2 at puberty. The estimated ingestion level is based on length at puberty in their staging atlas. We assume abundant food (of mother) for embryonic development in table 3.

Microscopic analysis of gonads revealed a remarkable effect of ingestion level on male gonads (figure 7): $f_{3}$ gonads were small empty shrivelled versions of healthy male testes such as those observed in $f_{1}$ and $f_{2}$. The analysis of female gonads was not conclusive. 

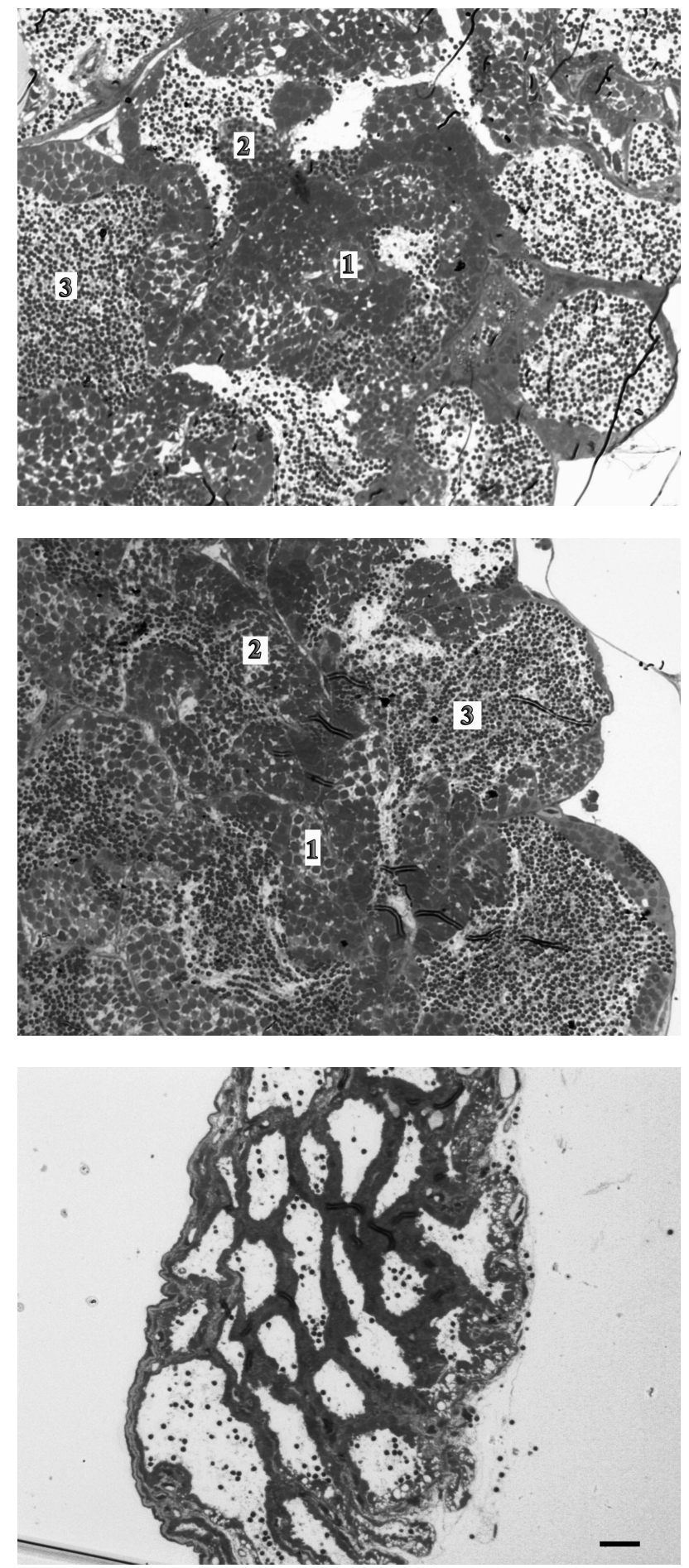

Figure 7: Microphotographs of male gonads after 82 days of caloric restriction for the ingestions levels $f_{1}$ (top), $f_{2}$ (middle) and $f_{3}$ (bottom). Scale bar: $20 \mu \mathrm{m} ; 1$ : cysts with secondary spermatogonia; 2 : cysts with spermatocytes; 3 : cysts with spermatids or spermatozoa. At $f_{3}$ structures are shrivelled. 


\section{Discussion}

Table 3: Cumulated energy invested in maturation, $E_{H}(\mathrm{~mJ})$ for the embryonic developmental milestones. Developmental stages and ages $\left(28.5^{\circ} \mathrm{C}\right)$ are as defined by Kimmel et al. (1995). Ages are presented in hours post-fertilization, hpf.

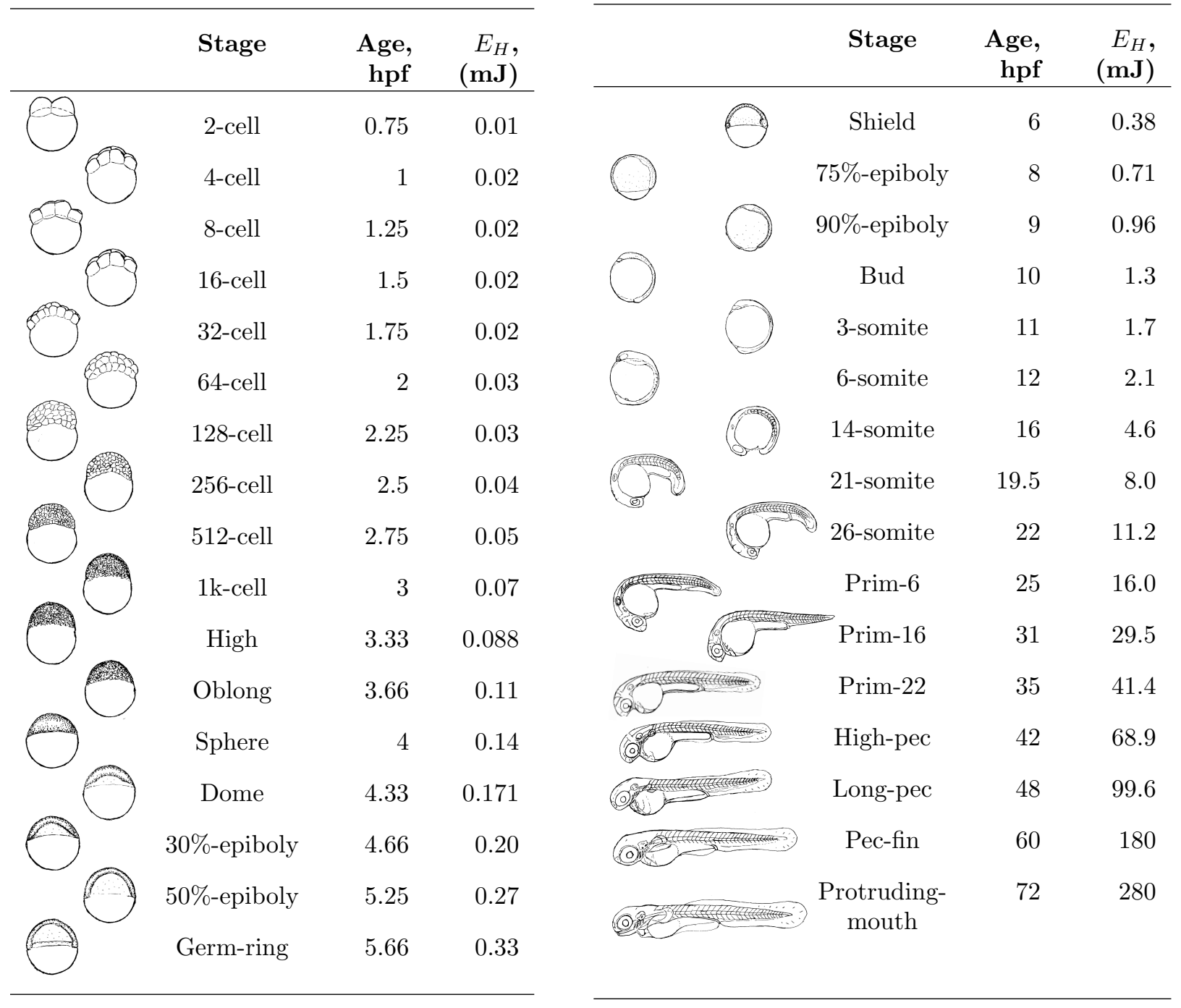

Reports of deviating growth patterns can be found in the literature which we briefly discuss here. Gómez-Requeni et al. (2010) observed growth arrest after 65 dpf, an age at puberty of around $50 \mathrm{dpf}$ and suggest that growth ceases during reproduction. This interpretation is at odds with other data (Barrionuevo and Burggren, 1999; Lawrence et al., 2008; Barrionuevo et al., 2010; Best et al., 2010) and our own experimental results; growth continues during reproduction at rates increasing with food level. Based on their growth data we estimate $f=0.88$ with an ultimate length of $4 \mathrm{~cm}$ TL and an age at puberty of $67 \mathrm{dpf}$. Zebrafish growth was found to be indeterminate Gerhard et al. (2002). Accordingly, we found that length still increased by a factor 1.3 after puberty at abundant 
Table 4: Maturity levels $E_{H}$ for post embryonic developmental milestones. Standard length SL (tip of snout till base of caudal fin), developmental stages and names as given in Parichy et al. (2009). Ages, in days post-fertilization (dpf), at $f=0.63$ and $f=1$ as well as SL at $f=1$ are model predictions at $28.5^{\circ} \mathrm{C}$.

\begin{tabular}{|c|c|c|c|c|c|c|}
\hline & STAGE & $\begin{array}{l}\text { age, } \\
\text { dpf }\end{array}$ & $\begin{array}{r}\mathrm{SL}^{a} \\
\mathbf{c m}\end{array}$ & $\begin{array}{l}\text { age, } \\
\text { dpf }\end{array}$ & $\begin{array}{l}\mathrm{SL}, \\
\mathrm{cm}\end{array}$ & $\begin{array}{l}E_{H} \\
(\mathrm{~J})\end{array}$ \\
\hline & & \multicolumn{2}{|c|}{$f=0.63$} & \multicolumn{2}{|c|}{$f=1$} & \\
\hline$\theta 0$ & pSB + swim bladder inflation ${ }^{b}$ & 4.5 & 3.8 & 4.0 & 3.7 & 0.5 \\
\hline$\theta 0$ & Fle early flexion & 7.2 & 4.5 & 6.3 & 4.6 & 1.1 \\
\hline 60 & CR caudal fin ray & 8.9 & 4.9 & 7.4 & 5.1 & 1.6 \\
\hline $02=2$ & AC anal fin condensation & 10.5 & 5.4 & 8.5 & 5.9 & 2.3 \\
\hline 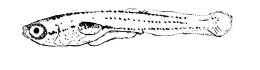 & DC dorsal fin condensation & 12.3 & 5.7 & 9.6 & 5.8 & 3.3 \\
\hline बre & $\begin{array}{l}\text { MMA metamorphic melanophore } \\
\text { appearance }\end{array}$ & 12.9 & 5.9 & 10.0 & 6.0 & 3.8 \\
\hline$\theta=0$ & AR anal fin ray appearance & 14.2 & 6.2 & 10.9 & 6.3 & 5 \\
\hline orot, $=3$ & DR dorsal fin ray appearance & 15.0 & 6.4 & 11.4 & 6.5 & 5.9 \\
\hline 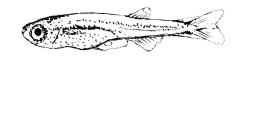 & $\begin{array}{l}\mathrm{PB}+\text { following pelvic fin bud } \\
\text { appearance }\end{array}$ & 18.7 & 7.6 & 13.8 & 7.7 & 12.7 \\
\hline 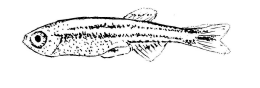 & PR pelvic fin ray appearance ${ }^{c}$ & 21.3 & 8.5 & 15.5 & 8.5 & 21.9 \\
\hline $0=a$ & $\begin{array}{l}\mathrm{PR}+\text { following pelvic fin ray } \\
\text { appearance }\end{array}$ & 22.5 & 9.2 & 16.3 & 9.3 & 27.9 \\
\hline 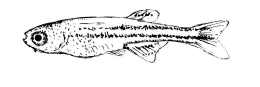 & SP onset of posterior squamation & 23.8 & 9.8 & 17.2 & 9.8 & 34.9 \\
\hline 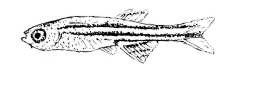 & SA onset of anterior squamation & 25.0 & 10.4 & 17.9 & 10.5 & 42.3 \\
\hline क & $\mathrm{J}$ juvenile & 26.2 & 11.0 & 18.7 & 11.0 & 50.9 \\
\hline 0 & $\mathrm{~J}+$ following juvenile & 30.8 & 13.0 & 21.6 & 13.2 & 91.7 \\
\hline 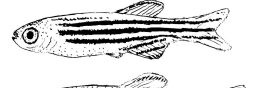 & $\mathrm{J}++$ following juvenile & 40.7 & 16.0 & 27.5 & 16.4 & 221.6 \\
\hline 0 & $=\mathrm{A}$ adults ${ }^{d}$ & 218 & 26.0 & 59.9 & 30.6 & 2061 \\
\hline
\end{tabular}

${ }^{a}$ Standardized Standard Lengths as given in Parichy et al. (2009)

${ }^{b}$ birth are defined by the DEB model

${ }^{c}$ maturity level just above metamorphosis as defined by the DEB model

${ }^{d}$ puberty as defined in the DEB model 
food.

Eaton and Farley (1974a); Schilling (2002); Best et al. (2010); Gómez-Requeni et al. (2010) observe juvenile growth that is consistent with our model predictions. Barrionuevo and Burggren (1999); Barrionuevo et al. (2010) however, observed growth arrest for about a month after birth $(\approx 4 \mathrm{~mm})$. They only started to feed the larvae when the yolk sac is completely absorbed, when zebrafish can begin actively feeding as soon the oesophagus opens and some of the yolk sac still remains (Lawrence, 2007; Best et al., 2010). Delaying initial feeding beyond this point impacts subsequent growth and survival (Guillaume et al., 1999). Except for a slow start, lengths and wet weight curves of Barrionuevo and Burggren (1999); Barrionuevo et al. (2010) are in agreement with our model predictions. During parameter estimation we assumed that all food types were equivalent. Practice teaches that food quality is an important parameter (Gergs and Rothhaupt, 2008) and it might contribute to deviation from general patterns. Moreover the model does not take digestion into account (i.e. gut residence time). The model can be extended to capture this aspect of physiology for certain applications (e.g. Evers and Kooijman, 1989).

If well fed individuals of sufficient size are exposed to $f=0.44$ computer simulations suggest that they should reproduce while growth is slightly negative. Pecquerie et al. (2009) consider that starved female Anchovy pay for somatic maintenance $\left(\left[\dot{p}_{M}\right]\right)$ by reabsorbing energy from the reproduction buffer. This is confirmed by our observations of male gonads. We implemented this behaviour in our simulation studies and growth will not become negative in the case of mild starvation.

Reproductive patterns are found highly variable compared to growth. Eaton and Farley (1974b) report a maximum of 60.4 eggs per day $\left(25.5^{\circ} \mathrm{C}, 497 \mathrm{dpf}\right)$ over a period of 105 days, Hisaoka and Firlit (1962) observe 37.9 eggs per day over a period of 146 days $\left(26^{\circ} \mathrm{C}\right)$ and Geffroy (unpublished data 2009) found 240 eggs per day over a 10 day period trial for zebrafish fed $5 \%$ their body weight $\left(25^{\circ} \mathrm{C}\right)$. Our study shows that the simultaneous observation of food intake, body size and reproductive output provides insight into the degree/nature of this variability. We present such information for individual zebrafish taken from the caloric restriction experiment (figure 6) and find results consistent with growth and first spawnings in Eaton and Farley (1974a). The detailed rules for spawning are part of the behavioural repertoire that can be rather stochastic and differ between individuals (Eaton and Farley, 1974b; Gerlach, 2006; Spence and Smith, 2006) calling for advanced statistical methods to detect metabolic perturbations (Paull et al., 2008). The reproduction buffer can contribute up to $15 \%$ of adult weight (Forbes et al., 2010). Reproduction increases with size, consistent with the finding of Uusi-Heikkila et al. (2010), and food availability. Our results show that that a large variability of the reproduction buffer handling rules can combine with a low variability of the reproduction rate.

Our assumption of a maternal effect is consistent with Brown (1958); Guillaume et al. (1999). It is not sure that this applies equally well to zebrafish. Forbes et al. (2010) suggest that egg size is decided during oocyte maturation and observe that higher food intake comes with the production of smaller eggs of poorer quality.

We measured egg dry mass of mature females (>364 dpf, $26^{\circ} \mathrm{C}$, ad libitum feeding) for each spawning event during a 2 month reproduction trial and found values ranging from 30 to $105 \mu \mathrm{g}$ (Augustine unpublished 2010). This large variation makes it difficult to 
judge the model assumption on the maternal effect. Future extensions of the model might include this variation.

The data did not allow us to study the effect of temperature outside the tolerance range as has been done for marine fish species (Freitas et al., 2010). We suggest that for ecological purposes such a study should be considered. Although our model correctly predicts survival patterns at a single ingestion level, predictions at other levels need confirmation. Reproduction might be impacted by age (Tsai et al., 2007), but more quantitative data is needed for modelling. Gold fish, Carassius aureatus, for example have maximum fertility at 3 years, become sterile by 7 and can live as long as 40 (Brown, 1958, pp.370). Effects of toxicants can be captured by linking parameter values to internal concentrations. This can also be done for density of damage compounds to model post reproductive periods (Jager and Klok, 2010; Kooijman, 2010).

We found that puberty, defined as the onset of allocation to reproduction, occurs above $f=0.6$. Lawrence et al. (2008) reported the appearance of secondary sexual characteristics after 4 months while we estimate an ingestion level of $f=0.49$ for some of the fish. Additionally, Schilling (2002) reported such characteristics at TL $=2-3 \mathrm{~cm}$ which is $20 \%$ lower than predicted. Secondary sexual characteristics might occur at a lower maturity level than for puberty; first spawning events (Eaton and Farley, 1974b) must occur later. The various events might be difficult to recognize accurately which can contribute to the discrepancies.

Even after correcting for effects of temperature, we demonstrated that developmental state at a particular age depends on feeding history. To a lesser extent developmental state at a particular size also depends on feeding history: better fed individuals reach puberty faster and at a larger size. This is in agreement with the observations of Parichy et al. (2009). The impact of food history accumulates over time (see table 4) and can become irreversible (Kooijman et al., 2011).

Variations in development play an important role in evolutionary theory (McKinney and McNamara, 1991). To study heterochrony it is necessary to distinguish between the "time" spent in a particular stage of development and the rate of growth within it. For instance, embryonic growth between 0.6 and $1.3 \mathrm{dpf}$ ( $13 \%$ of the embryonic period) is in the order of $3 \mathrm{~mm} \mathrm{~d}^{-1}$ (Kimmel et al., 1995) whereas growth rate between 18 and $40 \mathrm{dpf}$ in a high and low food regime is roughly 0.6 and $0.35 \mathrm{~mm} \mathrm{~d}^{-1}$ (Lawrence et al., 2008) and in all cases growth rate continues to decrease with age (under constant ingestion level). The lower area-specific maximum assimilation and reserve mobilization rates in an embryo can combine with the higher growth rate because volume linked somatic maintenance, which always takes precedence over growth in DEB theory, are very small for embryos relative to juveniles and adults (Kooijman et al., 2011). DEB theory offers the framework for changes in maturity throughout the life cycle that is consistent with observations. The use of reserve, being a good quantifier for metabolic activity, not directly translates in changes in maturity and/or size.

Reiss (1989) proposed 7 criteria which should be respected by a metric for developmental time: (1) independent of morphology, (2) independent of body size, (3) depend on one a priori homologous event, (4) unaffected by changes in temperature, (5) similar between closely related species, (6) increase with clock time, and (7) physically quantifiable. 
The maturity concept of DEB theory complies to all criteria. Parameter values are individual specific. Intra-species variations are small relative to inter-species variations and parameter values of similar species are similar (Kooijman, 2010). In the particular case that maturity maintenance $\dot{k}_{J} E_{H}$ is no longer be paid (starvation) rejuvenation can occur as has been observed in krill Euphausia superba (Thomas and Ikeda, 1987).

We show in this study that maturity is indirectly physically quantifiable see table 3 and 4 .

"Without a metric for developmental time the extent and meaning of evolutionary change in developmental timing simply cannot be assessed" (Reiss, 1989). We cannot agree more and suggest that maturity is a good candidate for such a metric. 


\section{A Electronic Appendix}

Graphs were digitalized using PlotReader ${ }^{\odot} 1.40 .0 .0$ (http://www.xs4all.nl/ jornbr/plotreader/) and then imported into the estimation procedure coded in Matlab ${ }^{\odot}$ (version 7.9.0.529). In addition to 1-variate data (e.g. length against time) we have added a number of 0-variate data (e.g. length at birth, egg size and dry weight).

For practical purposes DEBtool routines take compound parameters (simple function of primary parameters) and scaled variables as input.

Computations for 0-variate and 1-variate data from the literature all assume constant food and temperature.

Table A.1: Compound parameters (functions of primary energetic parameters) followed by parameters which link energies and lengths to (dry) mass. The latter are important in auxiliary theory.

\begin{tabular}{|c|c|c|c|c|}
\hline Symbol & Unit & Formulation & Value & Biological significance \\
\hline \multicolumn{5}{|c|}{ Compound parameters (functions of primary parameters) } \\
\hline$L_{m}$ & $\mathrm{~cm}$ & $\kappa \frac{\left\{\dot{p}_{A m}\right\}}{\left[\dot{p}_{m}\right\}}$ & 0.21 & Maximum structural length \\
\hline$\left[E_{m}\right]$ & $\mathrm{J} \mathrm{cm}^{-3}$ & $\frac{\left\{\dot{p}_{A m}\right\}}{\dot{v}}$ & 8860 & Maximum reserve density \\
\hline g & - & $\frac{\left[E_{G}\right] \dot{v}}{\kappa\left\{\dot{p}_{A m}\right\}}$ & 1.20 & Energy Investment Ratio \\
\hline$\dot{k}_{M}$ & $d^{-1}$ & $\begin{array}{l}\left.\frac{\left[\hat{p}_{m}\right]}{\left[E_{G}\right]}\right] \\
{\left[E_{G}\right]}\end{array}$ & 0.12 & Somatic maintenance rate coefficient \\
\hline$k$ & - & $\frac{\dot{k}_{J}}{k_{M}}$ & 0.15 & Maintenance ratio \\
\hline \multicolumn{5}{|c|}{ Auxilliairy parameters (used for calculating masses ${ }^{a}$ and volumes) } \\
\hline$w_{E}$ & $\mathrm{~g} \mathrm{~mol}^{-1}$ & Lika et al. (2011) & 23.9 & Molar weight of Reserve, E \\
\hline$w_{V}$ & $\mathrm{~g} \mathrm{~mol}^{-1}$ & Lika et al. (2011) & 23.9 & Molar weight of Structure, V \\
\hline$d_{E d}$ & $\mathrm{~g} \mathrm{~cm}^{-3}$ & Craig and Fletcher (1984) & 0.15 & Density of E \\
\hline$d_{V d}$ & $\mathrm{~g} \mathrm{~cm}^{-3}$ & Craig and Fletcher (1984) & 0.15 & Density of V \\
\hline$\mu_{E}$ & $\mathrm{~J} \mathrm{~mol}^{-1}$ & Lika et al. (2011) & 550000 & Chemical potential of $\mathrm{V}$ \\
\hline$\mu_{V}$ & $\mathrm{~J} \mathrm{~mol}^{-1}$ & Lika et al. (2011) & 500000 & Chemical potential of $\mathrm{E}$ \\
\hline
\end{tabular}

${ }^{a}$ used for calculating dry mass and we assume that wet mass $W_{w}=6 W_{d}$, with $W_{d}$ the dry mass

We work with the assumption that $d_{V d}=d_{E d}$ and consider that $d_{V}=1 \mathrm{gW}_{\mathrm{w}} \mathrm{cm}^{-3}$ and then derive $d_{V d}$ from observations in Craig and Fletcher (1984) using the following relationship: $d_{V d}=\frac{A F D W}{W_{w}} d_{V}$, with AFDW the ash free dry weight and $W_{W}$ the wet weight.

\section{A.1 Growth at constant food density}

The following equations are used to compute growth at constant food density. Table A.3 gives all quantities used below.

V1-morphic early juvenile stage: $a_{b} \leq a<a_{j}$ : 
Table A.2: Scaled variables of the DEB model used for computational purposes.

\begin{tabular}{lll}
\hline Variable & Unit & Name \\
\hline$e$ & - & scaled reserve density $\frac{E}{\left[E_{m}\right]}$ \\
$l$ & - & scaled structural length $\frac{L}{L_{m}}$ \\
$U_{H}$ & $\mathrm{~cm}^{2}$ day & scaled maturity level $\frac{E_{H}}{\left\{\dot{p}_{A m}\right\}}$ \\
$N$ & $\#$ & cumulative number of eggs \\
\hline
\end{tabular}

$$
\begin{aligned}
& L(a)=L_{b} \exp \left(\frac{\dot{r}_{V 1}}{3}\left(a-a_{b}\right)\right) \\
& a(L)=a_{b}+\frac{3}{\dot{r}_{V 1}} \ln \frac{L(a)}{L_{b}}
\end{aligned}
$$

and $\dot{r}_{V 1}=\frac{\dot{v}}{e+g}\left(\frac{e}{L_{b}}-\frac{1}{L_{m}}\right)$

Juvenile and adult stage: $a \geq a_{j}$ :

$$
\begin{aligned}
& L(a)=\mathrm{E}_{\infty}-\left(L_{\infty}-L_{j}\right) \exp \left(-\dot{r}_{B}\left(a-a_{j}\right)\right) \\
& a(L)=a_{j}+\frac{1}{\dot{r}_{B}} \ln \frac{L_{\infty}-L_{j}}{L_{\infty}-L(a)}
\end{aligned}
$$

and $\dot{r}_{B}=\frac{\dot{k}_{M} / 3}{1+e / g}$.

\section{A.2 Dynamic formulation of the model}

Dynamic formulation of the DEB model:

$$
\begin{aligned}
\frac{d e}{d t}= & \frac{\dot{v} \mathcal{M}(L)}{L}(f-e) \\
& \mathcal{M}(L)=\max \left(L_{b}, \min \left(L, L_{j}\right)\right) / L_{b} \text { and } f=0 \text { if } U_{H}<U_{H}^{b} \\
\frac{d L}{d t}= & \frac{L}{3} \frac{\dot{v}}{e+g}\left(\frac{e \mathcal{M}(L)}{L}-\frac{1}{L_{m}}\right) \\
\frac{d U_{H}}{d t}= & (1-\kappa) \frac{L^{3}}{1+g / e}\left(\frac{g \mathcal{M}(L)}{L}+\frac{1}{L_{m}}\right)-\dot{k}_{J} U_{H} \\
& \quad \text { if } \quad U_{H}<U_{H}^{P} \text { else } \frac{d U_{H}}{d t}=0 \\
\frac{d N}{d t}= & \frac{\kappa_{R}}{U_{E}^{0}}\left((1-\kappa) \frac{L^{3}}{1+g / e}\left(\frac{g}{L} \frac{L_{j}}{L_{b}}+\frac{1}{L_{m}}\right)-\dot{k}_{J} U_{H}^{P}\right) \\
& \quad \text { if } \quad U_{H}=U_{H}^{P} \text { else } \frac{d N}{d t}=0 \quad \text { and } U_{E}^{0}=E_{0} /\left\{\dot{p}_{A m}\right\}
\end{aligned}
$$


Table A.3: How all 0-variate data are computed in predict_Danio_rerio.

\begin{tabular}{|c|c|c|c|}
\hline Quantity & Symbol & Unit & DEBtool routine or formula \\
\hline \multicolumn{4}{|c|}{ Quantities calculated with DEBtool routines } \\
\hline Age at birth & $a_{b}$ & day & get_tb \\
\hline Length at birth & $L_{b}$ & $\mathrm{~cm}$ & get_tb \\
\hline Length at metamorphosis & $L_{j}$ & $\mathrm{~cm}$ & get_lj \\
\hline Length at puberty & $L_{p}$ & $\mathrm{~cm}$ & get_lj \\
\hline Mean life span & $a_{m}$ & day & get_tm_s \\
\hline Initial reserve & $E_{0}$ & $\mathrm{~J}$ & initial_scaled_reserve \\
\hline Maximum reproduction rate & $\dot{R}_{m}$ & $\#$ eggs day ${ }^{-1}$ & reprod_rate_metam \\
\hline \multicolumn{4}{|c|}{ Quantities which can be calculated analytically } \\
\hline Age at metamorphosis & $a_{j}$ & day & $a_{b}+3 / \dot{k}_{M} \frac{f / g+1}{f L_{m} / L_{b}-1} \ln \left(\frac{L_{j}}{L_{b}}\right)$ \\
\hline Ultimate length & $L_{\infty}$ & $\mathrm{cm}$ & $f L_{m} \frac{L_{j}}{L_{b}}$ \\
\hline Von Bert. growth rate & $\dot{r}_{B}$ & day $^{-1}$ & $\frac{\dot{k}_{M} / 3}{1+f / g}$ \\
\hline Age at puberty & $a_{p}$ & day & $a_{j}+\dot{r}_{B}^{-1} \frac{L_{\infty}-L_{j}}{L_{\infty}-L_{p}}$ \\
\hline \multicolumn{4}{|c|}{ Quantities which use auxilliary parameters } \\
\hline Maxium dry mass & $W_{d m}$ & g & $d_{V} L_{\infty}^{3}\left(1+\left(f+e_{R}\right) \frac{\left[E_{m}\right] w_{E}}{d_{V} \mu_{E}}\right)$ \\
\hline Egg dry mass & $W_{d}^{e g g}$ & $\mathrm{~g}$ & $E_{0} \frac{w_{E}}{\mu_{E}}$ \\
\hline Egg Volume & $V_{e g g}$ & $\mathrm{~cm}^{3}$ & $E_{0} \frac{w_{E}}{\mu_{E} d_{E}}$ \\
\hline Egg diameter & $\varnothing_{e g g}$ & $\mathrm{~cm}$ & $\left(\frac{6 V_{e g g}}{\pi}\right)^{\frac{1}{3}}$ \\
\hline Growth conversion efficiency & $\kappa_{G}$ & - & $\frac{\mu_{V} d_{V}}{\left[E_{G}\right] w_{V}}$ \\
\hline
\end{tabular}




\section{A.3 Survival probability}

The ageing module supposes short growth periods relative to life span, constant food density and negligible effects of ageing during the embryo stage (see Kooijman, 2010, pp.218):

$$
\dot{h}_{W}^{3}=\frac{\ddot{h}_{a} \dot{v}}{6 L_{m}} \quad \text { and } \quad \dot{h}_{G}=\frac{s_{G} f^{3} \dot{v}}{L_{m}}
$$

with $\dot{h}_{W}^{3}$ the Weibull ageing rate, and $\dot{h}_{G}$ the Gombertz ageing rate.

Survival probability is then expressed as:

$$
\operatorname{Pr}\{\underline{a}\}=\exp \left(\frac{6 \dot{h}_{W}^{3}}{\dot{h}_{G}^{3}}\left(1-\exp \left(\dot{h}_{G} t\right)+\dot{h}_{G} t+\frac{\dot{h}_{G}^{2} t^{2}}{2}\right)\right)
$$




\section{B Electronic Appendix}

A specific experimental system was custom designed to carry out this experiment (table B.1). The realisation of the aquariums was carried out by Sud Matière Plastique, Manosque. Each condition consists of a holding tank $(120 \times 25 \times 65 \mathrm{~cm} \mathrm{~L} \times \mathrm{W} \times \mathrm{H})$ containing 5 aquariums $(30 \times 28 \times 20 \mathrm{~cm} \mathrm{~L} \times \mathrm{W} \times \mathrm{H})$ which are permeable to the surrounding water (presence of fine slits along two opposite sides). Each aquarium is equipped with four removable mesh partitions separating the aquarium into four individual chambers. A hollow cylinder $(5 \mathrm{~cm} \varnothing)$ occupies the center of the aquarium and provides support for the removable partitions. A water distributor slides into the cylinder. Aquarium hosing is used for water renewal. Water is kept in 300L reservoirs and drawn with an immersible pump (Hydor). Hose connectors (Eheim) are used to link the hosing to the pumps and to each of the the water distributors. A removable screen perforated by $1 \mathrm{~mm}$ wide slits can be placed over the floor of an individual chamber during reproduction trials. The screen is put in place before the couple is formed to prevent egg predation. The system is made of plexiglass. Air stones linked to air pumps and immersed thermostat resistances maintain temperature and oxygen levels. About a quarter of the water is renewed each day.

The motivation behind this system was to (1) simultaneously observe the growth and reproduction of individual fish without removing the individuals during reproduction trials and (2) control the ingestion ration for each individual. After egg collection couples are separated by delicate insertion of the partition. This eliminates inter-individual ingestion competition. The partition is lifted in the evening, the perforated screen put over the floor on one side, fish are gently guided over the screen and then the partition is put back in place. The following morning the partition is lifted, fish swim to the other side, the partition is put back in place, the perforated screen is lifted, eggs are collected by gentle aspiration and finally fish are separated again during the day by replacing the partition. The reason the partitions were made of mesh was to maintain visual contact between the fish. Zebrafish are social animals and we feared they may lose appetite if kept in total isolation for long periods of time. 

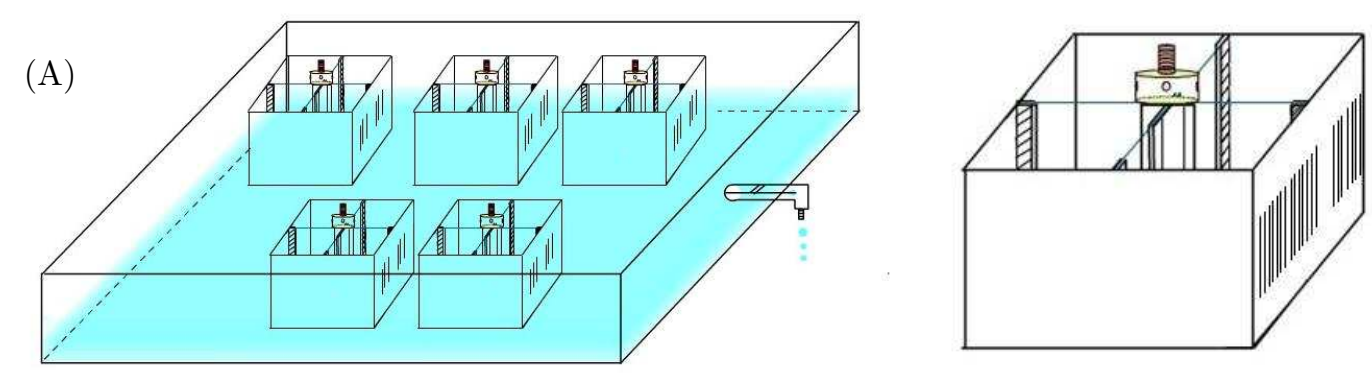

(B1)
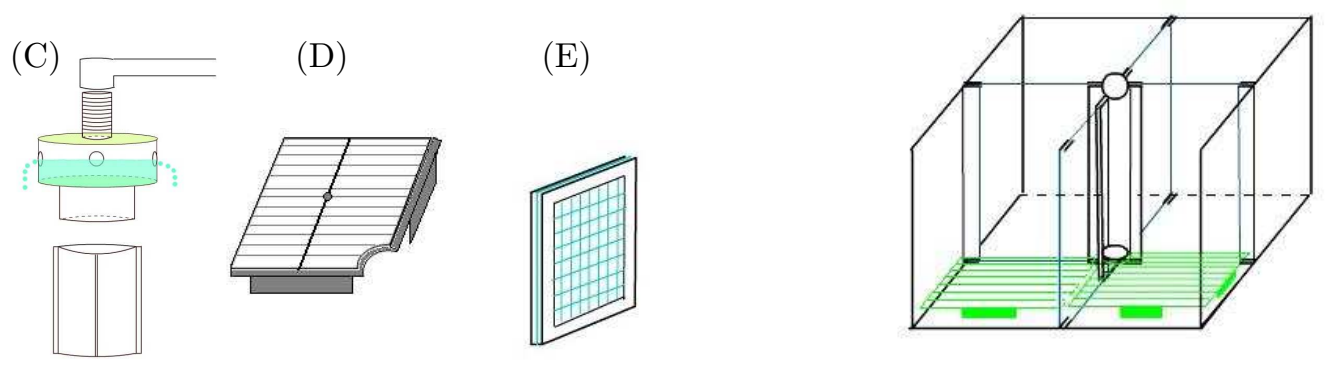

(B2)

Figure B.1: Experimental design of the caloric restriction experiment. Drawings are not to scale. (A) Holding tank (119 L) with 5 aquariums (each one is $13.4 \mathrm{~L}$ ) who are permeable to the surrounding water. 4 fish are maintained individually in each aquarium and put together as couples only in the evening. There are 3 experimental conditions so three of such holding tanks. (B1) Aquarium with four partitions, slits on the sides and water distributor. (B2) Transparent view of an aquarium with removable screens resting above the bottom of the aquarium which inhibit egg predation.(C) Close up of water distributor. (D) The removable screen used for reproduction trials. The screen is maintained some $5 \mathrm{~cm}$ from the bottom of the aquarium by a support system. Slits are $1 \mathrm{~mm}$ wide and allow eggs to pass through. (E) Close up of the removable mesh partition.

\section{Acknowledgements}

This work is part of the ENVIRHOM research program supported by the Insitute for Radioprotection and Nuclear Safety and the Provence Alpes Côte d'Azur region. We would like to thank N. Mente for contributing to the experimental design and the many authors who contributed their insights on zebrafish physiology in communications. We also thank two anonymous reviewers for their comments on an earlier version of the manuscript.

\section{References}

Bagatto, B., Pelster, B., and Burggren, W. W. (2001). Growth and metabolism of larval zebrafish: effects of swim training. J Exp Biol, 204:4335-4343. 
Barrionuevo, W. R. and Burggren, W. W. (1999). $\mathrm{O}_{2}$ consumption and heart rate in developing zebrafish (Danio rerio): Influence of temperature and ambient $\mathrm{O}_{2}$. Am J Physiol - Reg I, 276:505-513.

Barrionuevo, W. R., Fernandes, M. N., and Rocha, O. (2010). Aerobic and anaerobic metabolism for the zebrafish, Danio rerio, reared under normoxic and hypoxic conditions and exposed to acute hypoxia during development. Braz J Biol, 70:425-434.

Best, J., Adatto, I., Cockington, J., James, A., and Lawrence, C. (2010). A novel method for rearing firstfeeding larval zebrafish: polyculture with Type L saltwater rotifers (Brachionus plicatilis). Zebrafish, $7(3): 89-295$.

Bodiguel, X., Maury, O., Mellon-Duval, C., Roupsard, F., Le Guellec, A. M., and Loizeau, V. (2009). A dynamic and mechanistic model of PCB bioaccumulation in the European hake (Merluccius merluccius). J Sea Res, 62:124-134.

Brown, E. B. (1958). The physiology of fish. Volume I. Metabolism. Academic Press Inc., Publishers, New York.

Craig, J. F. and Fletcher, J. M. (1984). Growth and mortality of zebra fish, Brachydanio rerio (Hamilton Buchanan), maintained at two temperatures and on two diets. J Fish Biol, 25:43-55.

Eaton, R. C. and Farley, R. D. (1974a). Growth and the reduction of depensation of zebrafish, Brachydanio rerio, reared in the laboratory. Copeia, 1:204-209.

Eaton, R. C. and Farley, R. D. (1974b). Spawning cycle and egg production of zebrafish, Brachydanio rerio in the laboratory. Copeia, 1:195-204.

Evers, A. G. and Kooijman, S. A. L. M. (1989). Feeding, digestion and oxygen consumption in Daphnia magna a study in energy budgets. Neth $J$ Zoo, 39(1-2):56-78.

Flye-Sainte-Marie, J., Jean, F., Paillard, C., and Kooijman, S. A. L. M. (2009). A quantitative estimation of the energetic cost of brown ring disease in the Manila clam using Dynamic Energy Budget theory. $J$ Sea Res, 62:114-123.

Forbes, E. L., Preston, C. D., and Lokman, P. M. (2010). Zebrafish (Danio rerio) and the egg size versus egg number trade off: effects of ration size on fecundity are not mediated by orthologues of the Fec gene. Reprod Fert Develop, 22:1015-1021.

Freitas, V., Cardosa, J. F. M. F., Lika, K., Peck, M. A., Campos, J., Kooijman, S. A. L. M., and van der Veer, H. W. (2010). Temperature tolerance and energetics: a dynamic energy-based comparison of North Atlantic marine species. Philos Trans R Soc B, 365:3553-3565.

Gergs, R. and Rothhaupt, K. O. (2008). Feeding rates, assimilation efficiencies and growth of two amphipod species on biodeposited material from zebra mussels. Freshwater Biol, 53:2494-2503.

Gerhard, G. S. and Cheng, K. C. (2002). A call to fins! Zebrafish as a gerontological model. Aging Cell, 1:104-111.

Gerhard, G. S., Kauffman, E. J., Wang, X., Stewart, R., Moore, J. L., Kasales, C. J., Demidenko, E., and Cheng, K. C. (2002). Life spans and senescent phenotypes in two strains of Zebrafish (Danio rerio). Exp Gerontol, 37(8-9):1055-1068.

Gerlach, G. (2006). Pheromonal regulation of reproductive success in female zebrafish: female suppression and male enhancement. Anim Behav, 72:1119-1124. 
Gómez-Requeni, P., Conceição, L. E. C., Olderbakk Jordal, A. E., and Rønnestad, I. (2010). A reference growth curve for nutritional experiments in zebrafish (Danio rerio) and changes in whole body proteome during development. Fish Physiol Biochem, pages 1-17.

Guillaume, J., Kaushik, S., and Bergot, P. ant Métailler, R. (1999). Nutrition et alimentation des poissons et crustacés. INRA.

Hisaoka, K. K. and Firlit, C. F. (1962). Ovarian cycle and egg production in the zebrafish, Brachydanio rerio. Copeia, 4:788-792.

Jager, T. and Klok, C. (2010). Extrapolating toxic effects on individuals to the population level: the role of dynamic energy budgets. Philos Trans $R$ Soc B, 365:3531-3540.

Jusup, M., Klanjscek, T., Matsuda, H., and Kooijman, S. A. L. (2010). A full lifecycle bioenergetic model for bluefin tuna. in prep.

Kimmel, C. B., Ballard, W. W., Kimmel, S. R., Ullmann, B., and Schilling, T. F. (1995). Stages of embryonic development of the zebrafish. Dev Dynam, 203(3):253-310.

Kooijman, S. A. L. M. (2001). Quantitative aspects of metabolic organization: A discussion of concepts. Philos Trans R Soc B, 356(1407):331-349.

Kooijman, S. A. L. M. (2009). What the egg can tell us about its hen: Embryonic development on the basis of dynamic energy budgets. J Math Biol, 58(3):377-394.

Kooijman, S. A. L. M. (2010). Dynamic Energy Budget Theory for metabolic organization. Cambridge.

Kooijman, S. A. L. M., Pecquerie, L., Augustine, S., and Jusup, M. (2011). Scenarios for acceleration in fish development and the role of metamorphosis. J Sea Res. To appear.

Kooijman, S. A. L. M., Sousa, T., Pecquerie, L., Van der Meer, J., and Jager, T. (2008). From fooddependent statistics to metabolic parameters, a practical guide to the use of dynamic energy budget theory. Biol Rev, 83:533-552.

Laale, H. W. (1977). The biology and use of zebrafish, Brachydanio rerio in fisheries research. J Fish Biol, 10:121-173.

Lawrence, C. (2007). The husbandry of zebrafish (Danio rerio) : a review. Aquaculture, 269:1-20.

Lawrence, C., Ebersole, J. P., and Kesseli, R. V. (2008). Rapid growth and out-crossing promote female development in zebrafish (Danio rerio). Environ Biol Fish, 81:239-246.

Lika, K., Freitas, V., van der Veer, H. W., van der Meer, J., Wijsman, J. W. M., Pecquerie, L., Kearney, M. R., and Kooijman, S. A. L. M. (2011). Species diversity as reflected by the parameters of the standard DEB model: the covariation method of estimation. J Sea Res. To appear.

McKinney, M. L. and McNamara, K. J. (1991). Heterochrony : the evolution of ontogeny. Plenum Press, New York.

Parichy, D. M., Elizondo, M. R., Mills, M. G., Gordon, T. N., and Engeszer, R. E. (2009). Normal table of postembryonic zebrafish development: staging by externally visible anatomy of the living fish. Dev Dynam, 238:2975-3015.

Paull, G. C., Van Look, K. J. W., Santos, E. M., Filby, A. L., Gray, D. M., Nasha, J. P., and Tyler, C. R. (2008). Variability in measures of reproductive success in laboratory-kept colonies of zebrafish and implications for studies addressing population-level effects of environmental chemicals. Aquat Toxicol, $87: 115-126$. 
Pecquerie, L. (2007). Bioenergetic modelling of growth, development and reproduction of a small pelagic fish: the Bay of Biscay anchovy. PhD thesis, Agrocampus Rennes.

Pecquerie, L., Petitgas, P., and Kooijman, S. A. L. M. (2009). Modeling fish growth and reproduction in the context of the dynamic energy budget theory to predict environmental impact on anchovy spawning duration. J Sea Res, 62:93-105.

Reiss, J. O. (1989). The meaning of developmental time: a metric for comparative embryology. Am Nat, 134:170-189.

Rico-Villa, B., Bernard, I., Robert, R., and Pouvreau, S. (2010). A Dynamic Energy Budget (DEB) growth model for Pacific oyster larvae, Crassostrea gigas. Aquaculture, 305:84-94.

Schilling, T. F. (2002). The morphology of larval and adult zebrafish. In Nüsslein-Volhard, C. and Dahm, R., editors, Zebrafish: a practical guide., pages 59-83. Oxford University Press Inc., New York.

Shirone, R. C. and Gross, L. (1968). Effect of temperature on early embryological development of the zebra fish, Brachydanio rerio. J Exp Zool, 169:43-52.

Sousa, T., Domingos, T., Poggiale, J. C., and Koijman, S. A. L. (2010). Dynamic energy budget restores coherence in biology. Philos Trans $R$ Soc B, 365:3413-3428.

Spence, R., Gerlach, G., Lawrence, C., and Smith, C. (2008). The behaviour and ecology of the zebrafish, Danio rerio. Biol Rev, 83(1):13-34.

Spence, R. and Smith, C. (2006). Mating preference of female zebrafish, Danio rerio, in relation to male dominance. Behav Ecol, 17:779-783.

Spicer, J. I. and Burggren, W. W. (2003). Development of physiological regulatory systems: altering the timing of crucial events. Zoology, 106:91-99.

Thomas, P. G. and Ikeda, T. (1987). Sexual regression, shrinkage, re-maturation and growth of spent female Euphausia superba in the laboratory. Mar Biol, 95:357-363.

Tsai, S. B., Tucci, V., Uchiyama, J., Fabian, N. J., Lin, M. C., Bayliss, P. E., Neuberg, S., Zhanova, I. V., and Kishi, S. (2007). Differential effects of genotoxic stress on both concurrent body growth and gradual senescence in the adult zebrafish. Aging Cell, 6:209-224.

Uusi-Heikkila, S., Wolter, C., Meinelt, T., and Arlinghaus, R. (2010). Size-dependent reproductive success of wild zebrafish Danio rerio in the laboratory. J Fish Biol, 77:552-569.

van der Veer, H., Kooijman, S. A. L. M., and van der Meer, J. (2010). Intra- and interspecies comparaison of energy flow in the North Atlantic flatfish species by means of dynamic energy budgets. J Sea Res, 45:303-320.

van Leeuwen, I. M. M., Vera, J., and Wolkenhauer, O. (2010). Dynamic energy budget approaches for modelling organismal ageing. Philos Trans $R$ Soc B, 365:3443-3454.

Zonneveld, C. and Kooijman, S. A. L. M. (1993). Comparative kinetics of embryo development. Bull Math Biol, 3:609-635.

Information about the DEB research program and its results can be found at http: //www.bio.vu.nl/thb/deb/.

The Add_My_Pet collection can be found at http://www.bio.vu.nl/thb/deb/deblab/ add_my_pet/. 